\title{
Interactive Effects of Soybean Cyst Nematode, Arbuscular-Mycorrhizal Fungi, and Soil pH on Chlorophyll Content and Plant Growth of Soybean
}

\author{
Manhong Sun, ${ }^{1,2}$ Senyu Chen, ${ }^{1,3, \dagger}$ and James E. Kurle ${ }^{1}$ \\ ${ }^{1}$ Department of Plant Pathology, University of Minnesota, St. Paul, MN 55108, U.S.A. \\ ${ }^{2}$ Key Laboratory of Integrated Pest Management in Crops, Ministry of Agriculture, Institute of Plant Protection, Chinese Academy of \\ Agricultural Sciences, Beijing 100193, China \\ ${ }^{3}$ Southern Research and Outreach Center, University of Minnesota, Waseca, MN 56093, U.S.A.
}

Accepted for publication 30 June 2021

\begin{tabular}{|c|c|}
\hline \multicolumn{2}{|c|}{ ABSTRACT } \\
\hline $\begin{array}{l}\text { Nutritional deficiency chlorosis, especially iron-deficiency } \\
\text { chlorosis, and the soybean cyst nematode (SCN) limit soybean } \\
\text { yield. Arbuscular mycorrhizal fungi (MF) generally have beneficial } \\
\text { effects on plant growth. The interactive effects of SCN, MF, and } \\
\text { soil pH on leaf chlorophyll content (LCC) and growth of soybean } \\
\text { were examined in a greenhouse experiment. The experiment was } \\
\text { a randomized complete block design with three factors: SCN } \\
\text { population densities, MF inoculation, and soil pH levels. SCN } \\
\text { reduced LCC, and the effect increased with increasing time during } \\
5 \text { to } 9 \text { weeks after planting, especially in the high-pH (pH 8) soil. }\end{array}$ & $\begin{array}{l}\text { regardless of MF. MF increased shoot weight at } \mathrm{pH} 6.9 \text { and } \mathrm{pH} \\
8 \text { but not at } \mathrm{pH} 5.6 \text {. When MF was present, shoot weight was } \\
\text { generally highest at } \mathrm{pH} 6.9 \text {. At high } \mathrm{SCN} \text { when MF was absent, } \\
\text { plant growth was better in } \mathrm{pH} 5.6 \text { than } \mathrm{pH} 6.9 \text { and } \mathrm{pH} 8 \text { soils. This } \\
\text { study demonstrates that } \mathrm{SCN} \text { causes greater damage to soybean } \\
\text { when interacting with high } \mathrm{pH} \text {, and MF had a beneficial effect on } \\
\text { soybean growth regardless of SCN infection in all pH soils, in spite } \\
\text { of the negative effect of MF on LCC at approximately } 5 \text { to } 9 \text { weeks } \\
\text { after planting in high-pH soil at high SCN population density. }\end{array}$ \\
\hline $\begin{array}{l}\text { MF increased LCC in low-pH (pH 5.6) soil regardless of SCN } \\
\text { population density and in the high-pH soil without SCN. However, } \\
\text { MF reduced LCC if both pH and SCN population density were } \\
\text { high. The high-SCN population density (inoculation with } 10,000 \\
\text { eggs per } 100 \mathrm{~cm}^{3} \text { of soil) reduced soybean shoot weight in all soils }\end{array}$ & $\begin{array}{l}\text { Keywords: agriculture, arbuscular mycorrhizal fungi, chlorophyll } \\
\text { content, endophytes, Heterodera glycines, iron-deficiency } \\
\text { chlorosis, microbiome, nematology, plant pathology, plants, soil } \\
\text { ecology, soil pH, soybean, soybean cyst nematode, symbiosis, } \\
\text { yield and crop productivity }\end{array}$ \\
\hline
\end{tabular}

Chlorosis due to low chlorophyll content induced by nutritional deficiencies such as iron $(\mathrm{Fe})$, potassium, or nitrogen $(\mathrm{N})$ deficiencies is a common physiological disorder of soybean (Glycine max). Irondeficiency chlorosis (IDC) with characteristic interveinal chlorosis in new leaves (Brown 1963), in particular, is an important factor limiting soybean plant growth and yield in some areas of the north-central region of the United States such as Iowa, Minnesota, and North Dakota, where annual losses to IDC can be more than $\$ 120$ million (Hansen et al. 2003). Numerous studies have determined that IDC of soybean is associated with high soil $\mathrm{pH}$ and other soil abiotic factors,

\section{†Corresponding author: S. Chen; chenx099@umn.edu}

Funding: The research was supported by Minnesota Soybean Producers check-off funding through the Minnesota Soybean Research and Promotion Council and the Minnesota Agricultural Experiment Station.

The author(s) declare no conflict of interest.

(C) 2022 The American Phytopathological Society including high carbonate levels, high concentrations of soluble salts, low soil iron concentrations, and high soil $\mathrm{NO}_{3}$ (Bloom et al. 2011; Brown 1963; Franzen and Richardson 2000; Froechlich and Fehr 1981; Hansen et al. 2004, 2003; Inskeep and Bloom 1984, 1986, 1987; Kaiser et al. 2014; Liesch et al. 2012; Morris et al. 1990). A few studies showed that IDC is associated with biotic factors. Field surveys in Minnesota showed a correlation of IDC with the infestation by the soybean cyst nematode (SCN) (Hansen et al. 2004), which is the most damaging pest of soybean in most soybean-growing regions in the world (Monson and Schmitt 2004). In field plot experiments, IDC was less severe in SCN-resistant soybean cultivars than in SCNsusceptible cultivars, suggesting that SCN increased IDC severity (Charlson et al. 2004; Chen et al. 2007).

Crop sequence also influences the occurrence of IDC. Companion crops such as oat (Avena sativa) interseeded with soybean have been used to alleviate IDC by removing compounds such as $\mathrm{NO}_{3}$ that can promote IDC (Naeve 2006; Wallace 1988). In an investigation of the effect of a variety of crops on SCN population density, it was observed that IDC severity varied dramatically in the following 
soybean crop; little IDC occurred in soybean following canola (Brassica napus) and sugar beet (Beta vulgaris), whereas soybean following corn suffered severe IDC (Miller et al. 2006). This phenomenon was confirmed in another field plot experiment (Chen et al. 2013). However, the mechanism of the suppression of IDC by these two crops was not fully understood. We hypothesized that the suppression of IDC may be associated with the absence of vesiculararbuscular mycorrhizal fungi (MF) because canola and sugar beet are nonhosts of MF while all other crops tested in the study were hosts of MF. The experiment demonstrated that MF was positively correlated with IDC in the fields infested with SCN (Chen et al. 2013).

Vesicular-arbuscular MF are widely distributed in soils and form symbioses with more than $90 \%$ of plant species (Gadkar et al. 2001). The symbioses of MF and plants enhance plant uptake of minerals such as phosphorus (P), zinc, copper, and aluminum (Smith and Smith 1997) improve plant growth and increase plant tolerance to environmental stresses such as drought and pathogen infection (Naher et al. 2013; Porcel and Ruiz-Lozano 2004). Consequently, plants are expected to benefit most from the MF symbioses under adverse conditions, especially when $\mathrm{P}$ is a limiting factor in soil (Khalil et al. 1994). In soybean, both increase (Andrade et al. 2003) and decrease (Nogueira and Cardoso 2002) of Fe uptake by MF have been observed. In fact, the roles of MF in plant growth can range from mutualistic to parasitic depending on the stage of plant growth, soil nutrient status, and environmental factors (Johnson et al. 1997).

The effects of MF on plant-parasitic nematodes may be antagonistic or beneficial, depending on the specific association, soil nutrient level and timing of observation (Hol and Cook 2005; Ingham 1988). The direct effects include competition for nutrition and root space, modification of root exudates, alteration of plant physiology, colonization of nematode feeding sites, reduction in the number of giant cells, and release of nematoxins or antibiotics (Hol and Cook 2005; Ingham 1988; Suresh et al. 1985). Indirectly, the effects may be mediated through improved plant growth, offsetting yield loss normally caused by nematode infection.

A few studies have reported on the interaction between MF and SCN. Tylka et al. (1991) reported that MF suppressed SCN in an early plant growth period (before 49 days) in greenhouse pots but increased end-season SCN population density in microplots. A recent greenhouse study showed that all five species of MF tested effectively suppressed SCN population densities (Pawlowski and Hartman 2020). However, Francl and Dropkin (1985) reported that MF had little or no effect on SCN population densities in a field study. In another field study (Winkler et al. 1994) and greenhouse experiment (Todd et al. 2001), MF did not affect SCN population density but SCN negatively affected colonization of soybean roots by MF.

Cooccurrence of IDC and SCN in fields with high $\mathrm{pH}$ levels challenges the management tools available to farmers (Chen et al. 2007). In this study, greenhouse experiments were conducted to determine the interactive effects of $\mathrm{SCN}, \mathrm{MF}$, and soil $\mathrm{pH}$ on chlorophyll content and growth of soybean plants. A better understanding of the interactions of SCN, MF, and soil environment will enable development of effective integrated management tactics.

\section{MATERIALS AND METHODS}

Soil. Soil for the experiments was collected in a field in Waseca, MN, U.S.A., where studies of crop rotation and tillage effects on the SCN and soybean yield had been conducted (Chen 2007; Chen et al. 2001). Three soil samples of Webster Clay Loam designated as soil 1 , soil 2, and soil 3 were collected from the field at three locations that differed in $\mathrm{pH}$ and $\mathrm{Fe}$ but had a similar texture (Table 1). The soil was screened through a 5-mm-aperture sieve, and mixed with sand at 1:1 to increase drainage. The soil mixtures were pasteurized at $71^{\circ} \mathrm{C}$ in an autoclave for $1 \mathrm{~h}$, stored at room temperature for 1 week, and heat treated again at $71^{\circ} \mathrm{C}$ for $1 \mathrm{~h}$ before use.

Preparation of SCN inocula. A population of $\mathrm{SCN}$ race 3 (HG Type 0) that had been maintained on SCN-susceptible soybean cultivar Sturdy in the greenhouse for a number of years was used for inoculation. To increase the nematode population for use as inoculum in the experiment, the SCN-infested soil with some soybean roots was mixed with autoclaved sand (soil/sand $=1: 1, \mathrm{vol} / \mathrm{vol}$ ), and placed in 25 -cm-diameter clay pots. Soybean seed (Sturdy) were surface sterilized with $1 \% \mathrm{NaOCl}$ for $3 \mathrm{~min}$, and rinsed with distilled water three times. Approximately 20 seeds were sown in each pot, which was then maintained in the greenhouse with the temperature set at $28^{\circ} \mathrm{C}$. After 35 days, the soybean plants were removed and newly formed SCN females and cysts were washed off the roots through an $850-\mu \mathrm{m}$-aperture sieve with a vigorously applied water stream onto a $250-\mu \mathrm{m}$-aperture sieve. Females and cysts collected on the finer sieve were separated from debris by centrifugation in $63 \%$ (wt/vol) sucrose solution at $1,500 \times g$. Eggs were released from the cysts by crushing the cysts on a $150-\mu \mathrm{m}$-aperture sieve with a rubber stopper mounted on a motor (Faghihi and Ferris 2000), and collected on a 25- $\mu \mathrm{m}$ aperture sieve. The eggs were separated from debris by centrifugation in a $35 \%(\mathrm{wt} / \mathrm{vol})$ sucrose solution for $5 \mathrm{~min}$ at $1,500 \times \mathrm{g}$, collected in tap water, and used immediately or stored at $10^{\circ} \mathrm{C}$ for use the following day.

Preparation of MF inocula. Soil infested with MF was initially collected from a different area of the same field where the soil samples were collected. The species in the field MF community were identified, and the most abundant species were Glomus luteum and G. spurcum-like (Zhou 2009). The fungi were cultured on big bluestem grass (Andropogon gerardii) in plastic trays ( 45 by 35 by $12 \mathrm{~cm}$ ) in the greenhouse with the temperature set at 25 to $28^{\circ} \mathrm{C}$. Six holes were made in the bottom of the trays and a piece of filter paper was placed on each of the holes. A layer of $2 \mathrm{~cm}$ of autoclaved sand $\left(121^{\circ} \mathrm{C}, 2 \mathrm{~h}\right)$ was put in the trays for better drainage. The MF-infested field soil was passed through a 5-mm-aperture sieve and mixed thoroughly with autoclaved sand (soil/sand $=1: 1$, vol/vol). The trays were filled with the soil-sand mixture to a depth of $10 \mathrm{~cm}$.

Big bluestem grass seed, surface sterilized for 3 min with $1 \%$ $\mathrm{NaOCl}$ and then rinsed with distilled water three times, were evenly sown on the surface of the sand-soil mixture. Approximately 100 seeds were sown in each tray, covered with a 1-cm layer of sand-soil mixture, then covered with a $0.5-\mathrm{cm}$ layer of autoclaved sand. To prepare no-MF-infested grass roots, soil autoclaved for $2 \mathrm{~h}$ at $121^{\circ} \mathrm{C}$ was used instead of MF-infested soil. The trays with MF-infested and noninfested soils were placed on two separate benches in order to avoid cross contamination. The trays were watered daily and maintained at 25 to $28^{\circ} \mathrm{C}$. Basal plant nutrient solution $\left(\mathrm{K}_{2} \mathrm{SO}_{4}\right.$ at $75 \mathrm{mg} / \mathrm{kg}, \mathrm{NH}_{4} \mathrm{NO}_{3}$ at $25 \mathrm{mg} / \mathrm{kg}, \mathrm{CaCl}_{2}$ at $75 \mathrm{mg} / \mathrm{kg}, \mathrm{MgSO}_{4}$ at

TABLE 1

Characteristics of soils used in this study

\begin{tabular}{lccc}
\hline Soil variable & Soil 1 & Soil 2 & Soil 3 \\
\hline $\mathrm{pH}$ & 5.6 & 6.9 & 8.0 \\
\hline Organic matter (\%) & 5.5 & 6.1 & 7.5 \\
\hline Sand (\%) & 36 & 35 & 36 \\
\hline Silt (\%) & 33 & 34 & 34 \\
\hline Clay (\%) & 31 & 31 & 30 \\
\hline Phosphorus-Olson (ppm) & 7.3 & 8.1 & 4.9 \\
\hline Iron (ppm) & 135 & 42 & 12 \\
\hline Potassium (ppm) & 76 & 110 & 115 \\
\hline
\end{tabular}


$10 \mathrm{mg} / \mathrm{kg}$, and $\mathrm{ZnSO}_{4}$ at $5 \mathrm{mg} / \mathrm{kg}$ ) was added to the soil (100 ml/tray) three times at weeks 0,2 , and 4 after planting.

At 4 weeks after planting, the roots of big bluestem grass were sampled to detect MF colonization and sampled again every 2 weeks thereafter. Colonization of bluestem grass roots by MF was confirmed under a compound microscope by evaluating randomly selected root samples from both MF-inoculated plants and non-MF-inoculated plants. Lateral roots were cut into approximately $1-\mathrm{cm}$ segments and put into a cassette (approximately 20 to 50 segments in each cassette). The root samples were cleared in $10 \% \mathrm{KOH}$ solution at $121^{\circ} \mathrm{C}$ in an autoclave for a cycle of $8 \mathrm{~min}$ in a 1,000-ml beaker, rinsed with tap water for $1 \mathrm{~min}$, soaked in $10 \% \mathrm{HCl}$ solution for 1 to 2 min to acidify the samples, stained with $0.05 \%$ aniline blue at 60 to $70^{\circ} \mathrm{C}$ for $6 \mathrm{~min}$, and bleached with 70\% glycerol solution (Brundrett et al. 1996; Grace and Stribley 1991). Root samples were mounted in polyvinyl alcohollacto-glycerol on a slide (Koske and Tessier 1983) and the infection rate of grass roots was determined by a gridline intersect method (Giovannetti and Mosse 1980). Root tissue colonized by any of the fungal hyphae, vesicles, spores, or arbuscules was considered to be infected. At least 150 intersections from 15 root segments were examined for each sample.

The grass roots were harvested when a dense symbiosis was established. The root-soil mass was first cut into small pieces with a sawtooth knife; then, the roots were separated from soil and cut into 0.5- to $1-\mathrm{cm}$ segments using a Wiley Mill (Arthur H. Thomas Co.). Roots of big bluestem grass grown in autoclaved sand-soil mixture without addition of MF-infested soil served as the mock treatment. The root segments with minimum soil residue were stored in a refrigerator before use as inocula within 3 days.

Experimental design and setup. The experiment was arranged in a factorial design consisting of three SCN inoculation levels $(0$, 500 , and 10,000 eggs per $100 \mathrm{~cm}^{3}$ of soil), two MF treatments (MF and no-MF), and three different $\mathrm{pH}$ levels (pH 5.6, 6.9, and 8). Each treatment combination was replicated five times. Autoclaved soil was mixed thoroughly with the ground big bluestem grass roots in a plastic bag, then filled in 16-cm-diameter clay pots. Soybean cultivar 91M51, which is susceptible to SCN and was previously proved to have a high level of dependency on MF (M. Sun, unpublished data), was used. The soybean seed were surface sterilized with $3 \% \mathrm{NaOCl}$ for $3 \mathrm{~min}$, rinsed, and evenly coated with Rhizobium inocula (Royal Peat; Becker Underwood) before planting. In each pot, six soybean seeds were sown on the surface of soil containing either MF or no-MF inocula and covered with a layer of autoclaved soil. The pots were maintained in the greenhouse at an average temperature of $28^{\circ} \mathrm{C}$ with a day length of 16-h days and 8-h nights. After 1 week, the seedlings were thinned to three plants per pot. Two sets (10 pots) for each treatment combination were established. One set was used to determine biomass and SCN population densities 35 days after planting (DAP) and the other at 65 DAP. The 35- and 65-day periods provided sufficient time for both first and second generations, respectively, of SCN to develop. The experiment (Exp) was conducted twice in the greenhouse.

Data collection. Leaf chlorophyll. Soybean leaf chlorophyll contents (LCC) of the nine leaflets of the second trifoliolate leaves were measured for each plant using the SPAD 502 DL Meter (Minolta) at 35, 42, 49, 56, and 63 DAP, or weeks 5, 6, 7, 8, and 9, respectively. The average LCC meter reading for each pot was calculated from the nine observations.

Plant biomass. Plant biomass was measured 35 and 65 DAP from the two sets of pots. The plant shoots above the soil surface were cut and put in a paper bag. Soil with roots was removed from the pot and transferred to a container, where soybean roots were separated from the soil. The roots were carefully hand rubbed to dislodge the females and cysts from the roots but kept intact as much as possible. The roots were then rinsed with tap water to remove the soil, drained on tissue paper, and placed in a paper bag. The plant shoots and roots were then dried in an oven at $70^{\circ} \mathrm{C}$ for $72 \mathrm{~h}$ and weighed.

SCN population density. The soil from each pot was placed in a container and mixed thoroughly. A subsample of $100 \mathrm{~cm}^{3}$ was processed to determine SCN egg population density. The eggs were extracted using the same procedures as those described above for preparation of nematode inoculum.

MF colonization of soybean roots. Soybean root samples were collected from each pot in the first experiment, and colonization of the roots by MF was confirmed following the same procedures for the MF inoculum preparation.

Data analyses. The data were tested for normality and homogeneity of variance. The number of nematode eggs was transformed to $\ln (x)$ and percentage of roots colonized by MF was transformed to degree-arcsin$\left(x^{0.5}\right)$ to improve homogeneity of variance before being subjected to analysis of variance (ANOVA) with SAS V9.2 Proc GLM (SAS Institute, Cary, NC, U.S.A.). LCC and plant dry weight were not transformed for the ANOVA. Data of the two repeated experiments (Exp 1 and Exp 2) were initially combined for the ANOVA to determine whether experimental repetition interacted significantly with the experimental factors and whether the effect of experimental repetition was also significant. Because the interactions of experimental repetition with the factors were significant, the data of the two experiments were analyzed separately and the results of both experiments are presented. The means were separated by least significant difference test at $\alpha=0.05$.

\section{RESULTS}

Plant biomass. The interactions of experiment repetition with the individual factors of $\mathrm{SCN}, \mathrm{MF}$, soil $\mathrm{pH}$, and some of the combined factors affecting plant growth were significant (Table 2), indicating that other environmental factors (possibly temperature, humidity and light) differing between the two experiments interacted with these experimental factors. Because the three-way interactions were generally not significant, and there was no interaction between SCN and MF, the data of main effects of SCN (Fig. 1) and MF (Fig. 2) in different $\mathrm{pH}$ soils are presented.

Overall, there was a greater effect of SCN on plant growth in Exp 2 than in Exp 1 and, in general, the high SCN inoculation level reduced plant biomass. The effect of SCN on plant dry weight was similar between the MF treatments but differed among the three soil $\mathrm{pH}$ levels (Table 2; Fig. 1). The SCN inoculation level at 10,000 eggs per $100 \mathrm{~cm}^{3}$ of soil significantly reduced total plant dry weight as compared with the no-nematode control in almost all soils. The lower inoculation level at 500 eggs per $100 \mathrm{~cm}^{3}$ of soil had no or little effect on plant growth (Fig. 1).

The effect of MF on soybean growth differed among the two experiments, the three soils, and two sampling times (Table 2; Fig. 2). In general, MF increased shoot weight, especially in neutral and alkaline soils, in which a maximum was reached at $\mathrm{pH}$ 6.9. However, reduction of plant weight at 35 DAP was observed in $\mathrm{pH} 8$ soil when inoculated with 500 eggs per $100 \mathrm{~cm}^{3}$ of soil (data not shown).

Soil $\mathrm{pH}$ effect was quite different in the different treatments of MF and SCN (Fig. 3). In general, when MF was present, shoot weight was highest at $\mathrm{pH}$ 6.9. At the high SCN inoculation level (10,000 eggs per $100 \mathrm{~cm}^{3}$ of soil) when MF was absent, plant growth was better in $\mathrm{pH}$ 5.6 than $\mathrm{pH} 6.9$ and 8 soils. When both MF and SCN were absent, $\mathrm{pH}$ 5.6 resulted in lower plant weight than did pH 6.9 at 35 DAP in Exp 1. In contrast, the plant weight at 65 DAP was higher in $\mathrm{pH} 5.6$ than $\mathrm{pH}$ 8 soil in Exp 2 (Fig. 3). In the soil with low initial SCN population density (500 eggs per $100 \mathrm{~cm}^{3}$ of soil), the $\mathrm{pH}$ effect was similar to that in no-SCN soil (Fig. 3). 
Chlorophyll content and chlorosis. Overall, there were greater treatment effects in Exp 2 than in Exp 1. In Exp 1, all two-level interactions were significant in at least one of the five sampling times but there was no significant three-way interaction. In Exp 2, all threeway and two-way interactions, except for the MF-soil $\mathrm{pH}$ interaction, were significant at all five sampling times (Table 3). Consequently, the comparisons among individual treatments at one factor level are presented in Table 4.

Average LCC was greater in the MF than no-MF treatment at weeks 6 to 9 in both experiments (Table 3). However, the effect of MF on LCC differed at different SCN inoculation levels and at different $\mathrm{pH}$ levels (Table 4). MF generally increased LCC, especially in the soils with low or no SCN. However, the reduction of LCC by $\mathrm{MF}$ was detected in the high-pH soil with the high SCN level. In addition, reduction of LCC at week 5 by MF was detected in the $\mathrm{pH}$ 5.6 soil in Exp 1 and pH 6.9 soil in Exp 2 (Table 4).

Overall average LCC was lower in high-SCN than the low- or no-SCN soils at all sampling times in both experiments (Table 3). The effect of SCN on LCC, however, differed among the different $\mathrm{pH}$ soils and between the two MF treatments (Table 4). The high SCN inoculation level resulted in lower LCC in most MF-soil pH combinations but the low SCN inoculation level had no or little effect on LCC (Table 4).

The overall trend of soil $\mathrm{pH}$ effect on LCC is to decrease LCC with increasing soil $\mathrm{pH}$ (Tables 3 and 4). In the main effect, the $\mathrm{pH} 8$ soil resulted in lower LCC at all sampling times than the $\mathrm{pH} 5.6$ soil. The

TABLE 2

Analysis of variance (ANOVA) ( $F$ values) and comparisons in main effects on plant total dry weight (grams per pot) of soybean colonized or noncolonized by vesicular-arbuscular mycorrhizal fungi (MF) in three different $\mathrm{pH}$ soils infested with different population densities of the soybean cyst nematode (SCN) 35 and 65 days after planting ${ }^{2}$

\begin{tabular}{|c|c|c|c|c|c|}
\hline \multirow[b]{2}{*}{ Treatment } & \multirow[b]{2}{*}{$d f$} & \multicolumn{2}{|c|}{ Experiment 1} & \multicolumn{2}{|c|}{ Experiment 2} \\
\hline & & 35 days & 65 days & 35 days & 65 days \\
\hline \multicolumn{6}{|l|}{ ANOVA } \\
\hline $\mathrm{MF}(\mathrm{F})$ & 1 & 0.1 & $29.6^{* * * * *}$ & $9.5^{* *}$ & $92.2^{* * * *}$ \\
\hline $\operatorname{SCN}(N)$ & 2 & $17.3^{* * * *}$ & $116.8^{* * * *}$ & $40.5^{* * * *}$ & $202.2^{* * * *}$ \\
\hline Soil pH (S) & 2 & $43.6^{* * * *}$ & $4.4^{* *}$ & $8.1^{* * *}$ & $24.1^{* * * *}$ \\
\hline $\mathrm{F} \times \mathrm{N}$ & 2 & 2.4 & 2.6 & 2.4 & 0.3 \\
\hline $\mathrm{F} \times \mathrm{S}$ & 2 & $4.3^{*}$ & $13.1^{* * * *}$ & $6.6^{* *}$ & $6.6^{* *}$ \\
\hline $\mathrm{N} \times \mathrm{S}$ & 4 & 0.5 & $7.2^{* * * *}$ & 1.8 & $2.9 *$ \\
\hline $\mathrm{F} \times \mathrm{N} \times \mathrm{S}$ & 4 & 1.4 & 0.8 & $3.5 *$ & 0.9 \\
\hline \multicolumn{6}{|l|}{ Main effect } \\
\hline \multirow[t]{2}{*}{ MF } & No & $5.19 \mathrm{a}$ & $12.97 b$ & $4.21 \mathrm{~b}$ & $10.27 b$ \\
\hline & Yes & $5.22 \mathrm{a}$ & $15.83 \mathrm{a}$ & $4.87 \mathrm{a}$ & $14.98 \mathrm{a}$ \\
\hline \multirow[t]{3}{*}{$\mathrm{SCN}$} & 0 & $5.58 \mathrm{a}$ & $17.81 \mathrm{a}$ & $5.31 \mathrm{a}$ & $18.00 \mathrm{a}$ \\
\hline & 500 & $5.32 \mathrm{a}$ & $16.64 \mathrm{a}$ & $5.14 \mathrm{a}$ & $13.78 \mathrm{~b}$ \\
\hline & 10,000 & $4.73 \mathrm{~b}$ & $8.76 \mathrm{~b}$ & $3.17 \mathrm{~b}$ & $6.09 \mathrm{c}$ \\
\hline \multirow[t]{3}{*}{ Soil pH } & 5.6 & $4.50 \mathrm{c}$ & $15.12 \mathrm{a}$ & $4.67 \mathrm{a}$ & $14.36 \mathrm{a}$ \\
\hline & 6.9 & $5.88 \mathrm{a}$ & $14.77 \mathrm{a}$ & $4.99 a$ & $13.20 \mathrm{a}$ \\
\hline & 8.0 & $5.24 \mathrm{~b}$ & $13.32 \mathrm{~b}$ & $3.95 \mathrm{~b}$ & $10.31 \mathrm{~b}$ \\
\hline \multicolumn{6}{|c|}{$\begin{array}{l}{ }^{\mathrm{z}} \text { Asterisks } *, * *, * * *, \text { and } * * * * \text { represent significance of the ANOVA } \\
F \text { value at } P<0.05,0.01,0.001, \text { and } 0.0001 \text {, respectively. SCN } \\
\text { inoculation levels were } 0,500 \text {, and } 10,000 \text { eggs per } 100 \mathrm{~cm}^{3} \text { of soil. } \\
\text { Mean values followed by the same letters in the same column in the } \\
\text { same factor are not different according to the least significant } \\
\text { difference test at } P>0.05 \text {. }\end{array}$} \\
\hline
\end{tabular}

$\mathrm{pH} 6.9$ soil was associated with lower LCC than $\mathrm{pH} 5.6$ and higher LCC than $\mathrm{pH} 8$ in some sampling times but not all (Table 3). The effects of soil $\mathrm{pH}$ on LCC, however, differed in different SCN and MF treatments (Table 4). In general, there were greater $\mathrm{pH}$ effects on LCC in the SCN-infested soil than in no-SCN soil, and in the MF-infested soil than no-MF soil. In the soil infested with MF and high SCN, pH 8 was associated with much lower LCC when compared with the $\mathrm{pH} 5.6$ soil at all sampling times in both experiments. Particularly in Exp 2, approximately 50\% of reduction
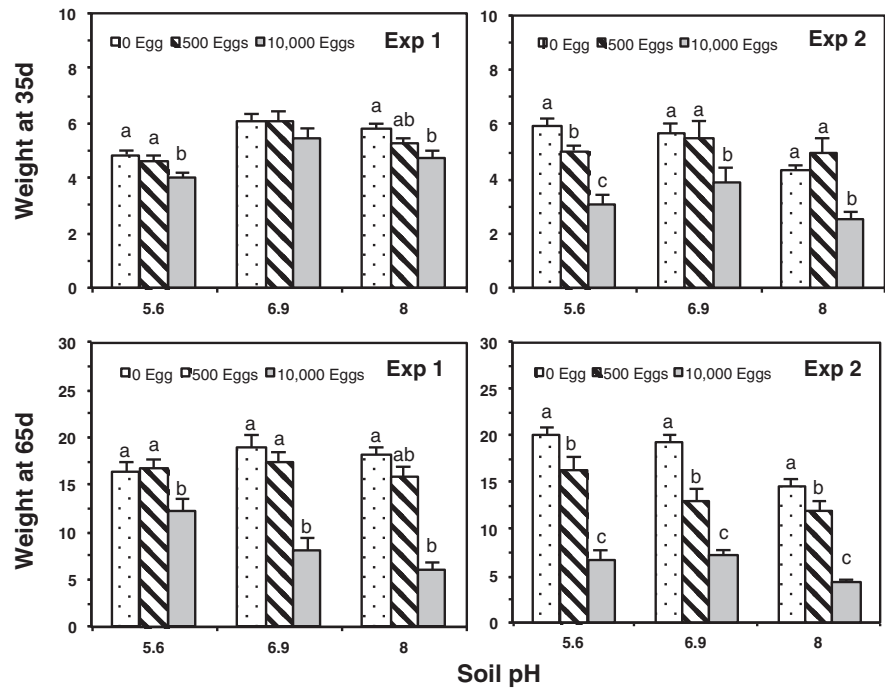

Fig. 1. Main effect of soybean cyst nematode inoculation $(0,500$, and 10,000 eggs per $100 \mathrm{~cm}^{3}$ of soil) on total dry weight (grams per pot) of soybean plants at 35 and 65 days after planting in three different $\mathrm{pH}$ soils with or without infestation of vesicular-arbuscular mycorrhizal fungi (MF). Data are means of MF and no-MF treatments with five replicates. Exp = experiment. The same letter or no letter on the bars within each soil in a graph denotes no significance according to the least significant difference test at $P>0.05$.
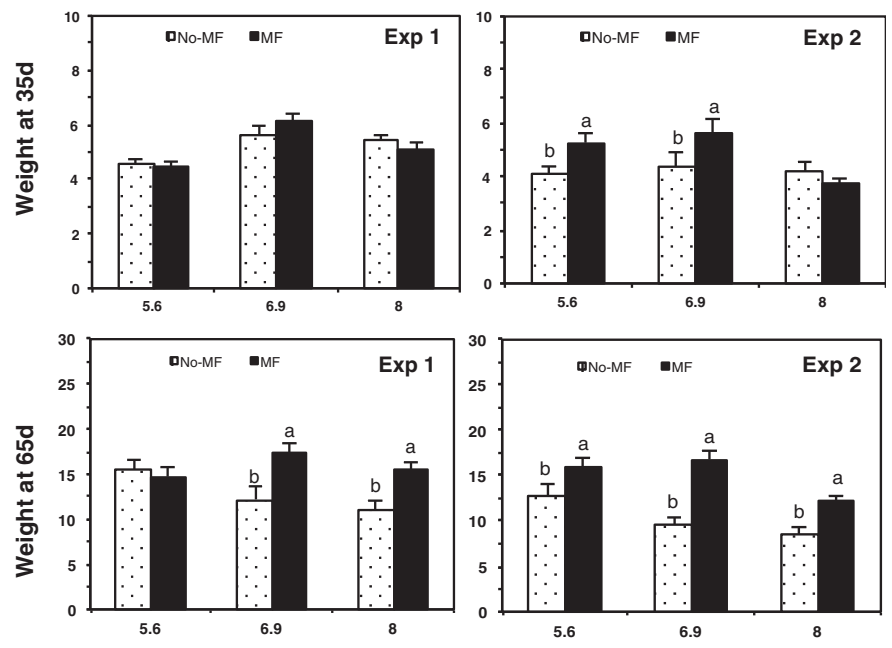

Soil pH

Fig. 2. Main effect of vesicular-arbuscular mycorrhizal fungi (MF) on total dry weight (grams per pot) of soybean plants at 35 and 65 days after planting in three different $\mathrm{pH}$ soils inoculated with different inoculation levels of soybean cyst nematode (SCN; 0, 500, and 10,000 eggs per $100 \mathrm{~cm}^{3}$ of soil). Data are means of the three SCN treatments with five replicates. Exp $=$ experiment. The same letter or no letter on the bars within each soil $(\mathrm{pH})$ in a graph denotes no significance according to the least significant difference test at $P>0.05$. 
of LCC was observed at the later sampling times at weeks 7 to 9. The soil of $\mathrm{pH} 6.9$ also reduced LCC as compared with $\mathrm{pH} 5.6$ at most sampling times (Table 4).

IDC symptoms of soybean plants were obvious in the $\mathrm{pH} 8$ soil infested with the high SCN population densities (Fig. 4). Although, sometimes, there were also a few chlorotic leaves on the soybean plants in the high-pH soils with no or low SCN population densities and in the lower-pH soils regardless of SCN infestation, the IDC symptoms were generally insignificant or there were not any IDC symptoms in these soils. Although there were not significant symptoms in most pots, the LCC was highly correlated $(P<0.0001$, data not shown) with plant biomass, the total plant dry weight at $65 \mathrm{DAP}$, and the correlation coefficient $(R)$ increased with later sampling times, with $R$ values ranged from 0.47 to 0.73 in Exp 1 and 0.47 to 0.69 in Exp 2 from weeks 5 to 9.

SCN population density. Overall, there was greater SCN reproduction in Exp 2 than in Exp 1; the average SCN egg population density 35 DAP (Pf35), which were the eggs of the first generation, was 3.3 times greater in $\operatorname{Exp} 2$ than in Exp 1. There were interactions, mostly the two-way interactions between SCN and MF or between $\mathrm{SCN}$ and soil pH (Table 5). Consequently, the data were analyzed for the low- and high-SCN inoculation levels separately, and the main effects of $\mathrm{MF}$ and soil $\mathrm{pH}$ at the individual $\mathrm{SCN}$ treatments are presented (Table 6). There were interactions of MF and soil $\mathrm{pH}$ for the SCN egg population density 65 DAP (Pf65), which included the eggs of the second generation, at the low SCN inoculation level in Exp 1 and at the high SCN inoculation level in Exp 2 (Tables 6 and 7). For SCN inoculation treatment effect, the data were analyzed at the individual MF-soil $\mathrm{pH}$ combinations (Table 8).

MF effect. MF effect on SCN population density differed at different SCN inoculation levels and between the two experiments (Table 6). At low SCN population densities, MF increased SCN population densities. In contrast, when SCN population densities were high, MF had no or negative effect on SCN population density (Tables 6 and 7).

Soil $\mathrm{pH}$ effect. In general, SCN population density increased with increasing soil $\mathrm{pH}$ when the $\mathrm{SCN}$ population density was low
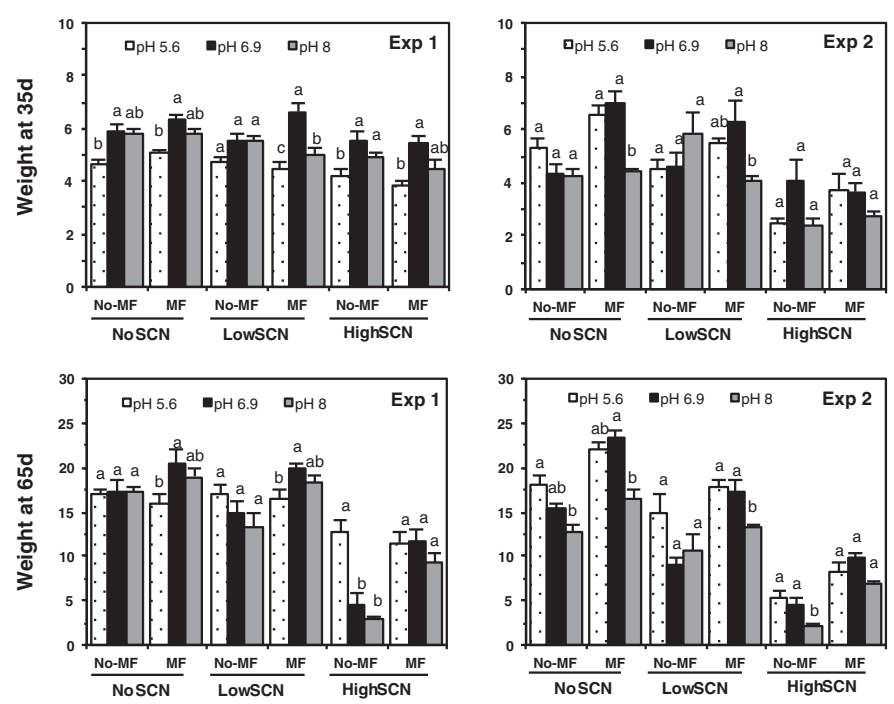

Fig. 3. Effect of pH in soils not infested or infested with the soybean cyst nematode (SCN; low SCN represents 500 eggs per $100 \mathrm{~cm}^{3}$ of soil and high SCN represents 10,000 eggs per $100 \mathrm{~cm}^{3}$ of soil) and vesiculararbuscular mycorrhizal fungi (MF) on total dry weight (grams per pot) of soybean plants at 35 and 65 days after planting. Data are means of five replicates. Exp = experiment. The same letter on the bars within combination of SCN and MF in a graph denotes no significance according to the least significant difference test at $P>0.05$.
(Table 6). At the low inoculation level in Exp 1, the SCN Pf35 in the $\mathrm{pH} 8$ soil were 7 times those in the $\mathrm{pH} 5.6$ soil and 4.7 times those in the $\mathrm{pH} 6.9$ soil. The difference among the soils became smaller at Pf65; on average, only approximately two times in either the $\mathrm{pH} 8$ or pH 6.9 as compared with pH 5.6 soil (Table 6). At the different SCN inoculation levels, there were interactions between the soil $\mathrm{pH}$ and $\mathrm{MF}$ at Pf65; lower $\mathrm{pH}$ did not always result in significantly lower Pf65 (Table 7).

SCN inoculation effect. The SCN Pf35 was greater in the high SCN inoculation level than the low inoculation level, although magnitude of difference differed among the MF and soil $\mathrm{pH}$ combinations (Table 8). There was less difference in SCN Pf65 between the two SCN inoculation treatments (Table 8). When reproduction rate was relatively low in Exp 1, significantly higher Pf65 were observed in the high-SCN treatment when compared with the low-SCN treatment in the no-MF, pH 5.6 soil. In contrast, lower Pf65 were observed in the higher SCN inoculation level in the $\mathrm{pH}$ 8 soil without MF and in the $\mathrm{pH} 5.6$ soil with MF in Exp 2, in which SCN reproduction rates were high (Table 8).

Percentage of roots colonized by MF. Percentage of roots colonized by MF did not differ among the three soil $\mathrm{pH}$ levels. However, inoculation with 10,000 eggs per $100 \mathrm{~cm}^{3}$ of soil resulted in a lower percentage $(74.7 \%$ ) of roots colonized by $\mathrm{MF}$ than inoculation with $0(85.3 \%)$ and $500(83.6 \%)$ eggs per $100 \mathrm{~cm}^{3}$ of soil.

\section{DISCUSSION}

Both SCN and IDC are major problems in soybean production and they often occur concomitantly in many fields in the north-central region in the United States (Chen et al. 2007). Previous studies have documented that both SCN and IDC are associated with high-pH soil, and SCN may enhance IDC in field conditions (Chen et al. 2007; Hansen et al. 2004). In this study, we demonstrated that the interaction between SCN and LCC differs in different $\mathrm{pH}$ soils, and their interaction is affected by MF. In some treatments, the LCC were reduced to a low level where chlorosis was obvious. Based on the chlorotic symptoms and the fact that the chlorosis occurred in the soil with a low soil Fe level (12 ppm), it appeared that the chlorosis was due to the deficiency of Fe; however, involvement of other nutrient deficiencies such as $\mathrm{N}$ deficiency cannot be ruled out.

Chlorosis is considered a symptom of soybean induced by SCN but limited research has demonstrated how SCN induces chlorosis. Although both a field survey (Hansen et al. 2004) and plot experiment (Chen et al. 2007) showed that SCN may increase IDC severity, this was the first study with controlled greenhouse experiments to demonstrate that $\mathrm{SCN}$ reduced chlorophyll contents and induced chlorosis in the high-pH soil where Fe levels were low. A recent report further demonstrated that chlorophyll was associated with tolerance to the nematode in soybean genotypes (Ravelombola et al. 2019).

Previous studies have shown that a preceding crop of canola (Chen et al. 2013) or rapeseed (Brassica napus) (Valetti et al. 2016) reduced colonization of soybean roots by MF, and IDC in soybean was less severe following the nonmycorrhizal host canola and sugar beet than following mycorrhizal crops (Chen et al. 2013). The present study supported our hypothesis that the suppression of IDC is associated with MF. However the effect of MF on IDC depends on soil factors and sampling time. MF had a negative effect on the chlorophyll content of soybean only in soil infested with a high SCN population density under the greenhouse conditions. This is probably due to damage to soybean roots by SCN resulting in insufficient Fe or other nutrient uptake for both plant and MF in the soil where the nutrient concentration is at a critical low level (e.g., Fe at 12 ppm) (Table 1). In 
these soils, Fe or other nutrient utilization by MF may reduce their availability for soybean growth, resulting in chlorotic symptoms of soybean at the plant growth stage at approximately weeks 6 to 7. It is also possible that SCN may compete with both MF and the plants for Fe or other nutrients, resulting in nutritional deficiency in the soybean plants in these soils.

High SCN population densities in fields are often associated with high-pH soil (Chen and Miller 2002; Pedersen et al. 2010) but the mechanism of the $\mathrm{pH}$ effect on $\mathrm{SCN}$ has not been fully studied. In the present study, we demonstrated that the $\mathrm{SCN}$ population densities 35 DAP were higher in high-pH than low-pH soil, suggesting that the reproduction of SCN was greater in high- than low-pH soil because these eggs were newly formed (first generation) and negligible mortality would have occurred. The effect of $\mathrm{pH}$ on $\mathrm{SCN}$ may interact with other soil factors, plant growth, and the initial SCN population densities. Population densities of the SCN second generation (Pf65) were highest in $\mathrm{pH} 6.9$ than $\mathrm{pH} 8$ soil. This was probably due to better plant growth in neutral $\mathrm{pH}$ soil that supported a greater SCN

TABLE 3

Analysis of variance (ANOVA) ( $F$ values) and comparisons in main effects on chlorophyll contents (chlorophyll meter reading) of soybean colonized or noncolonized by vesicular-arbuscular mycorrhizal fungi (MF) in three different pH soils infested with different population densities of the soybean cyst nematode $(\mathrm{SCN})^{2}$

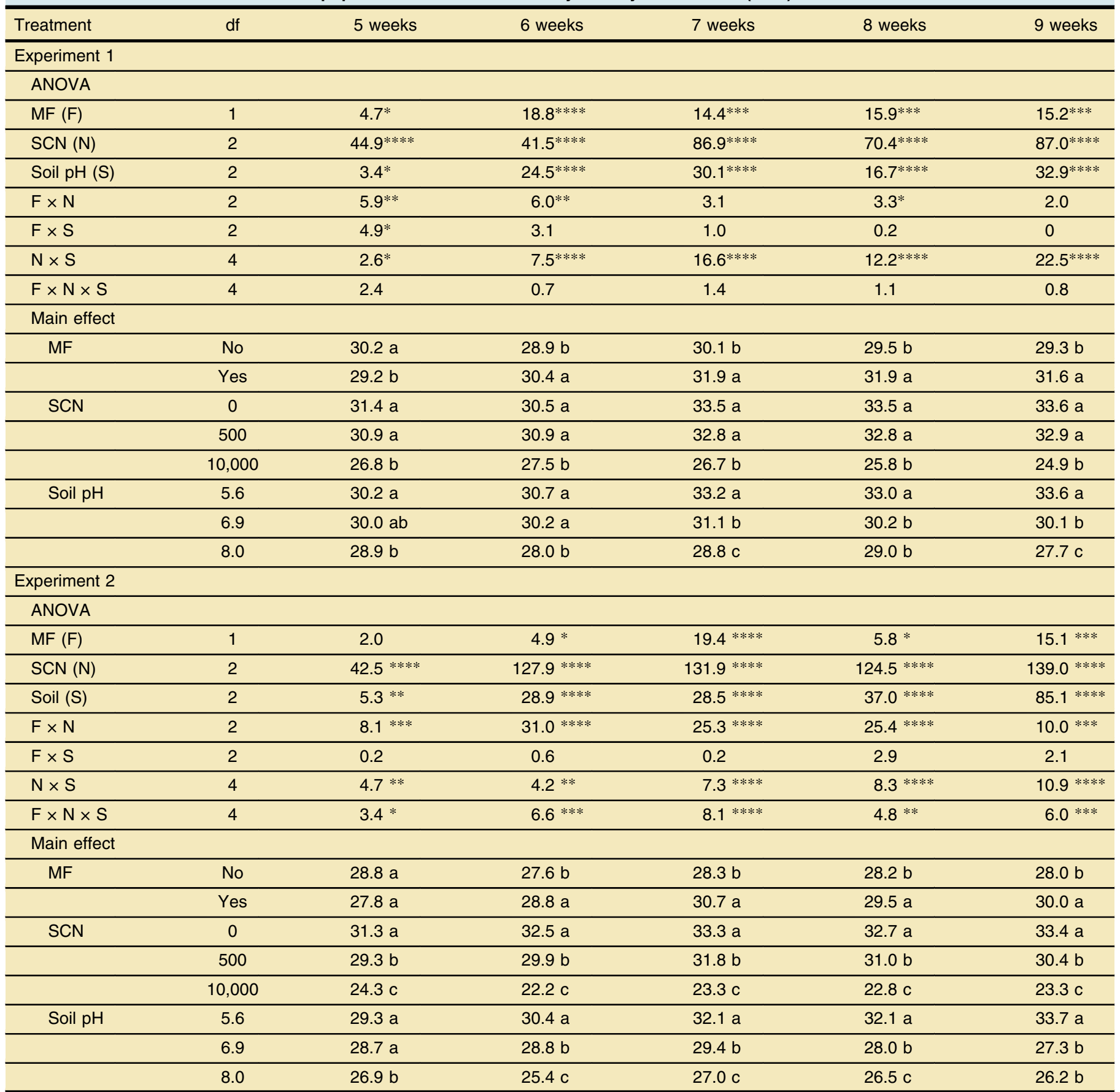

\footnotetext{
${ }^{\mathrm{z}}$ Asterisks *, **, ***, and **** represent significant of the ANOVA $F$ value at $P<0.05,0.01,0.001$, and 0.0001 , respectively. SCN inoculation levels were 0,500 , and 10,000 eggs per $100 \mathrm{~cm}^{3}$ of soil. Mean values followed by the same letters in the same column in the same factor are not different according to the least significant difference test at $P>0.05$.
} 
population. However, what stages of SCN life cycle are affected most by soil $\mathrm{pH}$ is still unclear.

MF have been shown to affect nematode populations (Hol and Cook 2005; Ingham 1988). Our study showed that the effect of MF on SCN depends on a combination of soil and environmental factors and plant growth stage. Both increase and decrease of SCN population density were observed in different $\mathrm{pH}$ soils and these differed in the repeated experiments, which may represent environmental conditions differing in day length and light intensity, temperature, and humidity. MF enhanced SCN population density in early plant growth stage at 35 DAP in Exp 1 but this was not consistently observed in Exp 2. It appeared that, in high-pH soil or with high SCN inoculation levels,
MF had a negative effect on SCN population density of the second generation. These results may explain the varied effects of MF on SCN population density in previous studies under different environments (Francl and Dropkin 1985; Pawlowski and Hartman 2020; Todd et al. 2001; Tylka et al. 1991; Winkler et al. 1994). MF may promote plant growth that can support a greater SCN population. On the other hand, MF can be antagonistic to nematodes through competition for root space and nutrients (Azcon and Barea 1996), through plant parasitism (Johnson et al. 1997) resulting in less photosynthate and nutrient availability for nematodes, or through colonization of cysts or parasitism of eggs (Francl and Dropkin 1985; Hu et al. 2018). The suppression of SCN by MF in the high-pH soil

TABLE 4

Interaction of soybean cyst nematode (SCN), vesicular-arbuscular mycorrhizal fungi (MF), and soil pH on chlorophyll content (chlorophyll meter reading) in soybean plants ${ }^{2}$

\begin{tabular}{|c|c|c|c|c|c|c|c|}
\hline Sampling time & Soil pH & \multicolumn{3}{|c|}{ No-MF } & \multicolumn{3}{|c|}{ MF } \\
\hline \multicolumn{8}{|l|}{ Experiment 1} \\
\hline \multirow{2}{*}{5 weeks } & 6.9 & $31.3 \mathrm{~A}$ & $31.0 \mathrm{~A}$ & 26.2 c B & $33.3 \mathrm{~A}$ & $30.9 \mathrm{AB}$ & 27.0 a B \\
\hline & 8.0 & $30.6 \mathrm{~A}$ & $30.3 \mathrm{~A}$ & 27.9 b B & $31.4 \mathrm{~A}$ & $30.8 \mathrm{~A}$ & $22.3 \mathrm{~b} \mathrm{~B}^{(* * *)}$ \\
\hline \multirow{2}{*}{6 weeks } & 6.9 & $30.3 \mathrm{~A}$ & $29.3 \mathrm{~A}$ & $27.2 \mathrm{ab} B$ & 32.5 a A* & 33.1 a $A * *$ & 28.7 a B \\
\hline & 8.0 & $29.1 \mathrm{~A}$ & $29.0 \mathrm{~A}$ & 25.4 b B & 29.9 b A & $31.5 \mathrm{~b} \mathrm{~A}$ & 23.4 b B \\
\hline \multirow[t]{3}{*}{7 weeks } & 5.6 & 32.4 & 32.4 & $31.4 \mathrm{a}$ & $35.3 *$ & 34.6 & $32.9 \mathrm{a}$ \\
\hline & 6.9 & $33.0 \mathrm{~A}$ & $31.0 \mathrm{~A}$ & 25.8 b B & $34.5 \mathrm{~A}$ & $34.4 \mathrm{~A}^{*}$ & 27.6 b B \\
\hline & 8.0 & $32.0 \mathrm{~A}$ & $30.5 \mathrm{~A}$ & $22.6 \mathrm{~b} \mathrm{~B}$ & $33.6 \mathrm{~A}$ & $34.0 \mathrm{~A}$ & $20.0 \mathrm{cB}^{(*)}$ \\
\hline \multirow[t]{3}{*}{9 weeks } & 5.6 & 32.9 & 32.0 & $32.1 \mathrm{a}$ & $34.9 *$ & $34.9 a b$ & $34.8 \mathrm{a}$ \\
\hline & 6.9 & $32.2 \mathrm{~A}$ & $31.0 \mathrm{~A}$ & $23.9 \mathrm{~b} B$ & $35.3 A^{*}$ & 35.6 a $A^{* *}$ & 22.6 b B \\
\hline & 8.0 & $31.7 \mathrm{~A}$ & $30.2 \mathrm{~A}$ & 17.5 c B & $34.9 \mathrm{~A}$ & $33.4 \mathrm{~b} \mathrm{~A}$ & $18.4 \mathrm{~b}$ \\
\hline \multicolumn{8}{|l|}{ Experiment 2} \\
\hline \multirow[t]{3}{*}{5 weeks } & 5.6 & $30.4 \mathrm{~b} \mathrm{~A}$ & 30.7 a $A$ & $27.3 \mathrm{~B}$ & $30.1 \mathrm{~A}$ & $30.4 \mathrm{~A}$ & 26.9 a B \\
\hline & 6.9 & 32.8 a $A$ & 30.4 a A & $25.0 \mathrm{~B}$ & $32.0 \mathrm{~A}$ & $31.8 \mathrm{~A}$ & 20.6 b B $^{(*)}$ \\
\hline & 8.0 & 33.2 a $A$ & $23.1 \mathrm{~b} \mathrm{~B}$ & $26.0 \mathrm{~B}$ & $29.0 \mathrm{~A}^{(*)}$ & $29.7 \mathrm{~A}$ & $20.1 \mathrm{~b} \mathrm{~B}^{(*)}$ \\
\hline \multirow[t]{2}{*}{6 weeks } & 5.6 & $30.7 \mathrm{~A}$ & 31.8 a A & $26.2 \mathrm{~B}$ & $35.1 \mathrm{ab} \mathrm{A*}$ & 33.9 a A & 24.7 a B \\
\hline & 6.9 & $30.4 \mathrm{~A}$ & 30.1 a $A$ & $23.4 \mathrm{~B}$ & 36.1 a $A^{* *}$ & $32.5 \mathrm{ab} A$ & 20.2 b B \\
\hline 8 weeks & 8.0 & $28.5 \mathrm{~b}$ & 26.1 & $22.7 \mathrm{~b}$ & $34.6 A^{*}$ & $32.6 \mathrm{ab} B$ & $14.7 \mathrm{~b} \mathrm{C}^{(* *)}$ \\
\hline \multirow[t]{3}{*}{9 weeks } & 5.6 & 34.2 a A & 33.1 a $A$ & 29.0 a B & 37.7 a $A^{*}$ & 34.6 a B & 33.5 a $B^{* *}$ \\
\hline & 6.9 & $32.0 \mathrm{ab} \mathrm{A}$ & 26.8 b B & $22.0 \mathrm{~b} \mathrm{C}$ & $33.3 \mathrm{~b} \mathrm{~A}$ & $31.2 b^{*}$ & $18.3 \mathrm{~b} \mathrm{~B}$ \\
\hline & 8.0 & 30.0 b A & 24.9 b B & 20.5 b C & $33.1 \mathrm{~b} \mathrm{~A}$ & $32.0 \mathrm{~b} \mathrm{~A}^{* *}$ & 16.5 b B $(P=0.06)$ \\
\hline
\end{tabular}

${ }^{\mathrm{z}}$ Asterisks *, **, ***, and ${ }^{* * * *}$ represent significance between the two MF treatments at the same pH and SCN inoculation levels (low and high SCN were 500 and 10,000 eggs per $100 \mathrm{~cm}^{3}$ of soil, respectively) according to the analysis of variance $F$ value at $P<0.05,0.01,0.001$, and 0.0001 , respectively; symbols without parenthesis indicate increase of chlorophyll content by MF and symbols in parentheses indicate reduction of chlorophyll content by MF. Mean values followed by the same lowercase letters in the same column or by the same uppercase letters in the same row in the same factor are not different according to the least significant difference test at $P>0.05$. 
with high SCN population density suggests the possibility that these conditions stress plants, and competition for nutrients may be intense between the root colonizers (i.e., SCN and MF) and the stressed plants (Johnson et al. 1997).

Suppression of MF by nematode infection has been reported in several studies (Elsen et al. 2003; Pinochet et al. 1996; Schreiner and Pinkerton 2008; Todd et al. 2001). In our study, we observed that SCN infection suppressed the percentage of soybean roots colonized by MF, which is similar to the results of Todd et al. (2001), who reported that colonization of soybean by the mycorrhizal fungus $G$. mosseae was reduced by infection with $\mathrm{SCN}$. Rodríguez-Echeverría et al. (2009) reported that the frequency of roots of dune grass (Ammophila arenaria) colonized by MF was unaffected by infection with Pratylenchus spp. nematodes but that the MF community

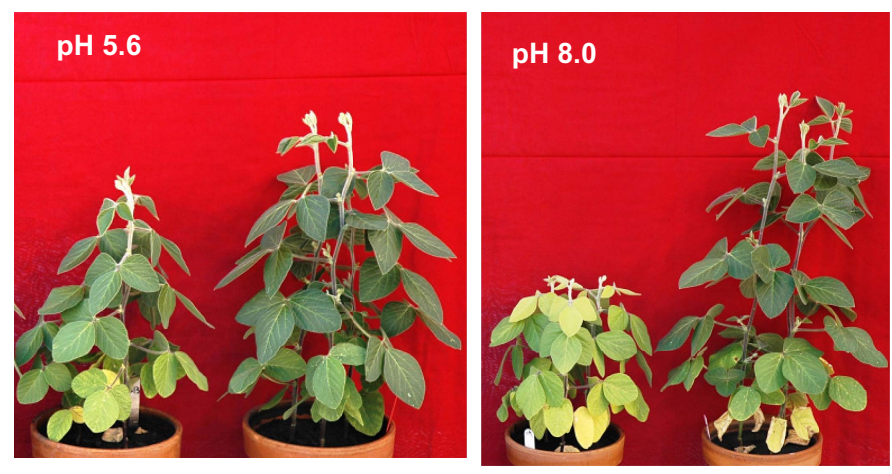

Fig. 4. Soybean plants exhibiting the interaction of the soybean cyst nematode (SCN) with high soil pH resulting in iron-deficiency chlorosis. Pot on left of each image was infested with 10,000 eggs per $100 \mathrm{~cm}^{3}$ of soil and pot on right had no SCN. structure was changed. The interaction between MF and nematodes may be species specific (Rodríguez-Echeverría et al. 2009). In our study, a field population with mixed MF species was used. The most abundant MF species in the community were in Glomus Group A based on the analysis of DNA sequences (Zhou 2009). However, the MF communities in the different treatments were not determined, and it is unclear whether or not SCN infection altered the MF community. The mechanisms of suppression of MF by $\mathrm{SCN}$ infection are unclear. It is possible that the SCN compete with MF for nutrition and space in plant roots or that the damaged roots are less suitable for MF colonization. Further studies are needed to test these hypotheses.

In our study, there was no effect of soil $\mathrm{pH}$ on MF colonization of soybean. In contrast, colonization of black gram (Vigna mungo) by MF was best at soil pH 6 to 7, and both alkaline and acidic soils reduced MF colonization (Sankaranarayanan et al. 2001). Although soil $\mathrm{pH}$ may affect colonization of host plants by MF, it is difficult to predict the effect of $\mathrm{pH}$ on $\mathrm{MF}$ population with any certainty (Frey and Ellis 1997).

Soybean growth and yield are determined by many factors. Soil $\mathrm{pH}$ is an important factor determining soybean yield because it affects the availability of essential nutrients and soil biological activities (Pedersen et al. 2010; Peters et al. 2005; Schulte et al. 2005). A soil $\mathrm{pH}$ from 6.3 to approximately neutral is required for an optimum yield production (Peters et al. 2005). SCN and IDC are two extensively studied yield-suppressive factors, whereas MF is generally considered a beneficial factor. This study demonstrated the interactive effects of $\mathrm{SCN}, \mathrm{MF}$, and soil $\mathrm{pH}$ on LCC and plant biomass. Our study showed that LCC was highly correlated with plant biomass, suggesting that the chlorosis is an important yield-suppressive factor, while the LCC is affected by the interactions of SCN, MF, and soil $\mathrm{pH}$. This study provides useful information for developing effective strategies to manage SCN and nutrient deficiencies, especially IDC, in different

TABLE 5

Analysis of variance (ANOVA) and comparisons in main effects of egg population density of the soybean cyst nematode (SCN) 35 and 65 days after planting (Pf35 and Pf65, respectively) in three different pH soils inoculated with or without vesicular-arbuscular mycorrhizal fungi (MF) and infested with different initial SCN population densities ${ }^{z}$

\begin{tabular}{|c|c|c|c|c|c|}
\hline Comparisons & $\mathrm{df}$ & \multicolumn{2}{|c|}{ Experiment 1} & \multicolumn{2}{|c|}{ Experiment 2} \\
\hline \multicolumn{6}{|l|}{ ANOVA } \\
\hline $\mathrm{SCN}(\mathrm{N})$ & 1 & $80.6^{* * * *}$ & 0.1 & $235.5^{* * * *}$ & $40.7^{* * * *}$ \\
\hline Soil pH (S) & 2 & $30.2^{* * * *}$ & $8.1^{* *}$ & $6.9^{* *}$ & $3.8^{*}$ \\
\hline$F \times S$ & 2 & 0.3 & 0.5 & 2.6 & 2.1 \\
\hline $\mathrm{N} \times \mathrm{S}$ & 2 & $6.5^{* *}$ & 0.3 & $5.5^{* *}$ & $4.8^{*}$ \\
\hline $\mathrm{F} \times \mathrm{N} \times \mathrm{S}$ & 2 & 0.7 & 2.9 & 0.9 & $5.4^{* *}$ \\
\hline \multicolumn{6}{|l|}{ Main effect } \\
\hline MF & No & $13,579 \mathrm{~b}$ & $223,382 \mathrm{a}$ & $45,901 \mathrm{a}$ & $361,770 \mathrm{a}$ \\
\hline \multirow[t]{3}{*}{ Soil pH } & 5.6 & $6,503 \mathrm{c}$ & $134,761 \mathrm{~b}$ & $27,957 \mathrm{c}$ & $236,273 \mathrm{~b}$ \\
\hline & 6.9 & $14,905 \mathrm{~b}$ & $241,733 a$ & 62,707 a & $337,907 \mathrm{a}$ \\
\hline & 8.0 & 20,592 a & 195,338 a & $48,490 \mathrm{~b}$ & 242,362 b \\
\hline
\end{tabular}

\footnotetext{
${ }^{\mathrm{z}}$ Asterisks *,**,***, and **** represent significant of the ANOVA $F$ value at $P<0.05,0.01,0.001$, and 0.0001 , respectively. SCN inoculation levels were 500 or 10,000 eggs per $100 \mathrm{~cm}^{3}$ of soil. Mean values followed by the same letters in the same column in the same factor are not different according to the least significant difference test at $P>0.05$.
} 
soils. For example, in a low-pH soil, $\mathrm{SCN}$-resistant soybean cultivars may be used if the SCN population densities are above damaging level. In the high-pH soil infested by SCN, especially with low soil Fe levels, cultivars carrying the IDC-tolerance trait along with SCN resistance may be required for effective protection of soybean crop yield.

The patterns of treatment on nematode population, MF, and plant growth were similar between the two repeated experiments, although there were significant interactions between the experiments and the treatments. The significant interactions were probably due to the differences in some greenhouse environmental conditions, especially temperature and light between the two experiments associated with seasonal changes in day length and sunlight intensity. The first experiment was conducted during the winter from November to January and the repeated experiment was conducted in early spring from February to May. Although the greenhouse temperature was set at $28^{\circ} \mathrm{C}$ during both experiments, differences in insolation and outside temperatures between the two experiments likely resulted in warmer temperatures as spring progressed. The most important environmental factors for the difference in SCN reproduction between the experiments were probably the seasonal differences in light intensity and quality, and temperature. SCN reproduction potential in the greenhouse is generally lower during winter as compared with other seasons. Lower SCN reproduction in the first experiment was probably due, in large part, to greater dormancy in winter (Sommerville and Davey 2002; Zheng and Ferris 1991), resulting in lower numbers of hatched second-stage juveniles to infect the plants. Hill and Schmitt (1989) showed that slight variations in temperature could affect nematode reproduction under greenhouse conditions, and the temperature during the second experiment was likely more favorable to $\mathrm{SCN}$ reproduction. Based on the results of plant biomass measured in soil colonized by MF but not SCN, the environment in the second

TABLE 7

Interactive effect of vesicular-arbuscular mycorrhizal fungi (MF) and soil pH on final population density of soybean cyst nematode (SCN) (eggs per $100 \mathrm{~cm}^{3}$ of soil) at 65 days (Pf65) after planting ${ }^{2}$

\begin{tabular}{lccccc}
\hline & \multicolumn{2}{c}{ Experiment 1, low SCN } & & \multicolumn{2}{c}{ Experiment 2, high SCN } \\
\cline { 2 - 3 } \cline { 6 - 6 } Soil pH & No-MF & MF & & No-MF & MF \\
\hline 5.6 & $81,772 \mathrm{~b}$ & $142,050 \mathrm{a}$ & & $166,346 \mathrm{~b}$ & $54,200 \mathrm{~b}^{*}$ \\
\hline 6.9 & $271,276 \mathrm{a}$ & $206,141 \mathrm{a}$ & & $408,407 \mathrm{a}$ & $136,207 \mathrm{a}^{*}$ \\
\hline 8.0 & $226,548 \mathrm{a}$ & $187,678 \mathrm{a}$ & & $133,558 \mathrm{~b}$ & $127,165 \mathrm{a}$ \\
\hline
\end{tabular}

${ }^{\mathrm{z}}$ An asterisk $(*)$ represents significance between the two MF treatments according to the analysis of variance $F$ value at $P<0.05$. Low and high SCN were inoculation levels at 500 and 10,000 eggs per $100 \mathrm{~cm}^{3}$ of soil, respectively. Values followed by the same letter in the same column are not different according to the least significant difference test at $P>0.05$

TABLE 6

Analysis of variance (ANOVA) and comparisons in main effects on final egg population density (eggs per $100 \mathrm{~cm}^{3}$ of soil) of the soybean cyst nematode (SCN) 35 and 65 days after planting (Pf35 and Pf65, respectively) in three different pH soils inoculated with or without vesicular-arbuscular mycorrhizal fungi (MF), separately at low (500 eggs per $100 \mathrm{~cm}^{3}$ of soil) and high $\left(10,000\right.$ eggs per $100 \mathrm{~cm}^{3}$ of soil) SCN inoculation levels ${ }^{2}$

\begin{tabular}{|c|c|c|c|c|c|}
\hline \multirow[b]{2}{*}{ Comparisons } & \multirow[b]{2}{*}{ df } & \multicolumn{2}{|c|}{ Experiment 1} & \multicolumn{2}{|c|}{ Experiment 2} \\
\hline & & Pf35 & Pf65 & Pf35 & Pf65 \\
\hline \multicolumn{6}{|l|}{ Low SCN } \\
\hline MF (F) & 1 & $7.50^{*}$ & 0.05 & 2.73 & $15.52 * * *$ \\
\hline Soil pH (S) & 2 & $36.82 * * * *$ & $7.27^{* *}$ & 0.26 & 0.12 \\
\hline \multicolumn{6}{|l|}{ Main effect } \\
\hline \multirow[t]{2}{*}{ MF } & No & $4,833 \mathrm{~b}$ & $193,199 \mathrm{a}$ & $11,844 \mathrm{a}$ & $487,437 a$ \\
\hline & Yes & $7,478 a$ & $178,623 \mathrm{a}$ & $9,105 \mathrm{a}$ & 259,324 b \\
\hline \multirow[t]{2}{*}{ Soil pH } & 5.6 & $1,938 \mathrm{c}$ & $111,911 \mathrm{~b}$ & $9,921 \mathrm{a}$ & $362,273 \mathrm{a}$ \\
\hline & 6.9 & $2,883 \mathrm{~b}$ & $238,709 a$ & $11,686 \mathrm{a}$ & $403,507 \mathrm{a}$ \\
\hline \multicolumn{6}{|l|}{ ANOVA } \\
\hline MF (F) & 1 & 0.27 & 2.43 & $10.11 * *$ & $22.08^{* * *}$ \\
\hline Soil pH (S) & 2 & $4.57^{*}$ & $13.53^{*}$ & 2.50 & $11.52^{* * *}$ \\
\hline$F \times S$ & 2 & 0.19 & 3.46 & 0.44 & $5.37^{*}$ \\
\hline \multicolumn{6}{|l|}{ Main effect } \\
\hline \multirow[t]{2}{*}{ MF } & No & 22,326 a & 79,958 a & $253,565 \mathrm{a}$ & $236,104 \mathrm{a}$ \\
\hline & Yes & $21,363 \mathrm{a}$ & 84,632 a & $137,056 \mathrm{~b}$ & 105,857 b \\
\hline \multirow[t]{3}{*}{ Soil pH } & 5.6 & $11,068 \mathrm{~b}$ & $45,994 \mathrm{~b}$ & $157,611 \mathrm{a}$ & $110,273 \mathrm{~b}$ \\
\hline & 6.9 & 26,927 a & $113,728 a$ & 244,758 a & $272,307 \mathrm{a}$ \\
\hline & 8.0 & $27,538 \mathrm{a}$ & 87,163 a & $183,563 a$ & 130,362 b \\
\hline
\end{tabular}

\footnotetext{
${ }^{z}$ Asterisks *, **, ***, and $* * * *$ represent significant of the ANOVA $F$ value at $P<0.05,0.01,0.001$, and 0.0001 , respectively. Mean values followed
} by the same letters in the same column in the same factor are not different according to the least significant difference test at $P>0.05$. 
TABLE 8

Effect of soybean cyst nematode (SCN) inoculation level on the SCN population density at 35 and 65 days after planting (Pf35 and Pf65, respectively) ${ }^{z}$

\begin{tabular}{|c|c|c|c|c|c|}
\hline Mycorrhizal fungi & Soil pH & \multicolumn{2}{|c|}{ Pf35 } & \multicolumn{2}{|c|}{ Pf65 } \\
\hline \multicolumn{6}{|l|}{ Experiment 1} \\
\hline \multirow{2}{*}{ No } & 6.9 & 1,937 & 29,477 & 271,276 & 289,576 \\
\hline & 8.0 & $11,629 \mathrm{~b}$ & 25,495 a & 226,548 & 235,748 \\
\hline \multirow{2}{*}{ Yes } & 6.9 & $3,828 \mathrm{~b}$ & 24,377 a & 206,141 & 199,941 \\
\hline & 8.0 & $15,662 \mathrm{~b}$ & 29,582 a & 187,678 & 131,378 \\
\hline \multicolumn{6}{|l|}{ Experiment 2} \\
\hline \multirow[t]{2}{*}{ No } & 5.6 & $10,237 \mathrm{~b}$ & 30,695 a & 384,346 & 166,346 \\
\hline & 6.9 & $12,978 \mathrm{~b}$ & $123,060 \mathrm{a}$ & 566,407 & 408,407 \\
\hline Yes & 8.0 & $7,319 b$ & 88,208 a & 197,165 & 127,165 \\
\hline
\end{tabular}

experiment was also more favorable for plant growth. This was probably due to greater light intensity and higher temperatures, which benefitted soybean plant growth during the early spring. The better plant growth can also be one of the factors that contributed to greater SCN reproduction in the second experiment. Although it was not determined whether there was difference in MF colonization between the two experiments, environmental factors such as temperature and light intensity are known to affect MF (Latef et al. 2016). Due to the effect of greenhouse environmental factors on plant growth, SCN population development, and possibly $\mathrm{MF}$ colonization as well, it is unsurprising that the interactions among the SCN, MF, and soil $\mathrm{pH}$ on the soybean LCC and growth were slightly different between the two experiments. Additional experiments are needed to determine how environmental conditions affect the interactions of SCN, MF, and soil $\mathrm{pH}$.

Conclusion. This study demonstrated that the effect of SCN and MF on soybean LCC and biomass differed in different $\mathrm{pH}$ soil. At low $\mathrm{pH} 5.6$ or in neutral-pH soil where soil Fe nutrient was sufficient, SCN had little effect on LCC. At high soil $\mathrm{pH}(\mathrm{pH} 8)$ where Fe level was low, the LCC was dramatically reduced and the high SCN infestation (inoculation with 10,000 eggs per $100 \mathrm{~cm}^{3}$ of soil) accelerated the suppression of LCC, resulting in chlorotic symptoms. MF were beneficial to plant growth as measured with LCC in all $\mathrm{pH}$ soils where there was no or low SCN population density or in the low$\mathrm{pH}$ soils even infested by the high SCN population density. However, MF reduced LCC when the SCN population density was high in the high-pH soil. The high SCN population density reduced shoot weight of soybean in all soils regardless of MF. MF increased shoot weight at $\mathrm{pH} 6.9$ and $\mathrm{pH} 8$ but not at $\mathrm{pH}$ 5.6. When MF was present, shoot weight was generally highest at $\mathrm{pH}$ 6.9. At high $\mathrm{SCN}$ when MF was absent, plant growth was better in $\mathrm{pH} 5.6$ than $\mathrm{pH} 6.9$ and 8 soils. This study demonstrates that $\mathrm{SCN}$ causes greater damage to soybean when interacting with high $\mathrm{pH}$, and MF had a beneficial effect on soybean growth regardless of SCN infection in all $\mathrm{pH}$ soils, in spite of the negative effect of MF on LCC in the soil with the high $\mathrm{pH}$ and SCN population density. This study provides useful information for developing effective strategies to manage SCN and nutrient deficiencies, especially IDC, in different soils.

\section{ACKNOWLEDGMENTS}

We thank S. Lewandowski, S. Huerd, C. Johnson, and W. Gottschalk for technical assistance; and P. Schaus for providing soybean cultivars.

\section{LITERATURE CITED}

Andrade, S. A. L., Abreu, C. A., Abreu, M. F., and Silveira, A. P. D. 2003. Interação de chumbo, da saturação por bases do solo e de micorriza arbuscular no crescimento e nutrição mineral da soja [Interaction between lead, soil base saturation rate, and mycorrhiza on soybean development and mineral nutrition]. Rev. Bras. Ciênc. Solo 27:945-954.

Azcon, A. C., and Barea, J. M. 1996. Arbuscular mycorrhizas and biological control of soil-borne plant pathogens - an overview of the mechanisms involved. Mycorrhiza 6:457-464.

Bloom, P. R., Rehm, G. W., Lamb, J. A., and Scobbie, A. J. 2011. Soil nitrate is a causative factor in iron deficiency chlorosis in soybeans. Soil Sci. Soc. Am. J. 75:2233-2241.

Brown, J. C. 1963. Interactions involving nutrient elements. Annu. Rev. Plant Physiol. 14:93-106.

Brundrett, M., Bougher, N., Dell, B., Brave, T., and Malajczuk, N. 1996. Working with mycorrhizas in forestry and agriculture. Aust. Cent. Int. Agric. Res. Monogr. 32:179-183.

Charlson, D. V., Bailey, T. B., Cianzio, S. R., and Shoemaker, R. C. 2004. Breeding soybean for resistance to iron-deficiency chlorosis and soybean cyst nematode. Soil Sci. Plant Nutr. 50:1055-1062.

Chen, S. 2007. Tillage and crop sequence effects on Heterodera glycines and soybean yields. Agron. J. 99:797-807.

Chen, S., Kurle, J. E., Stetina, S. R., Miller, D. R., Klossner, L. D., Nelson, G. A., and Hansen, N. C. 2007. Interactions between iron-deficiency chlorosis and soybean cyst nematode in Minnesota soybean fields. Plant Soil 299:131-139.

Chen, S., Kurle, J. E., Sun, M., Naeve, S., Wyse, D. L., and Stahl, L. A. 2013. Preceding crops affected soybean iron-deficiency chlorosis and vesiculararbuscular mycorrhizal fungi in soybean cyst nematode-infested fields. Crop Sci. 53:250-259. 
Chen, S., and Miller, D. 2002. Effects of soil pH on Heterodera glycines reproduction and soybean chlorosis. (Abstr.) Nematology 4:251.

Chen, S., Porter, P. M., Reese, C. D., and Stienstra, W. C. 2001. Crop sequence effects on soybean cyst nematode and soybean and corn yields. Crop Sci. 41: 1843-1849.

Elsen, A., Baimey, H., Sweenen, R., and De Waele, D. 2003. Relative mycorrhizal dependency and mycorrhiza-nematode interaction in banana cultivars (Musa spp.) differing in nematode susceptibility. Plant Soil 256:303-313.

Faghihi, J., and Ferris, J. M. 2000. An efficient new device to release eggs from Heterodera glycines. J. Nematol. 32:411-413.

Francl, L. J., and Dropkin, V. H. 1985. Glomus fasciculatum, a weak pathogen of Heterodera glycines. J. Nematol. 17:470-475.

Franzen, D. W., and Richardson, J. L. 2000. Soil factors affecting iron chlorosis of soybean in the Red River Valley of North Dakota and Minnesota. J. Plant Nutr. 23:67-78.

Frey, J. E., and Ellis, J. R. 1997. Relationship of soil properties and soil amendments to response of Glomus intraradices and soybeans. Can. J. Bot. 75:483-491.

Froechlich, D. M., and Fehr, W. R. 1981. Agronomic performance of soybeans with differing levels of iron deficiency chlorosis on calcareous soil. Crop Sci. 21:438-441.

Gadkar, V., David-Schwartz, R., Kunik, T., and Kapulnik, Y. 2001. Arbuscular mycorrhizal fungal colonization. Factors involved in host recognition. Plant Physiol. 127:1493-1499.

Giovannetti, M., and Mosse, B. 1980. An evaluation of techniques for measuring vesicular arbuscular mycorrhizal infection in roots. New Phytol. 84:489-500.

Grace, C., and Stribley, D. P. 1991. A safer procedure for routine staining of vesicular-arbuscular mycorrhizal fungi. Mycol. Res. 95:1160-1162.

Hansen, N. C., Jolley, V. D., Naeve, S. L., and Goos, R. J. 2004. Iron deficiency of soybean in the north central US and associated soil properties. Soil Sci. Plant Nutr. 50:983-987.

Hansen, N. C., Schmitt, M. A., Anderson, J. E., and Strock, J. S. 2003. Iron deficiency of soybean in the Upper Midwest and associated soil properties. Agron. J. 95:1595-1601.

Hill, N. S., and Schmitt, D. P. 1989. Influence of temperature and soybean phenology on dormancy induction of Heterodera glycines. J. Nematol. 21: 361-369.

Hol, W. H. G., and Cook, R. 2005. An overview of arbuscular mycorrhizal fungi-nematode interactions. Basic Appl. Ecol. 6:489-503.

Hu, W., Strom, N., Rajendran, D., Chen, S., and Bushley, K. 2018. Mycobiome of cysts of the soybean cyst nematode under long term crop rotation. Front. Microbiol. 9:386.

Ingham, R. E. 1988. Interactions between nematodes and vesicular-arbuscular mycorrhizae. Agric. Ecosyst. Environ. 24:169-182.

Inskeep, W. P., and Bloom, P. R. 1984. A comparative study of soil solution chemistry associated with chlorotic and nonchlorotic soybean in western Minnesota. J. Plant Nutr. 7:513-531.

Inskeep, W. P., and Bloom, P. R. 1986. Effects of soil moisture on soil $p \mathrm{CO}_{2}$, soil solution bicarbonate and iron chlorosis in soybeans. Soil Sci. Soc. Am. J. 50:946-952.

Inskeep, W. P., and Bloom, P. R. 1987. Soil chemical factors associated with soybean chlorosis in Calciaquolls of western Minnesota. Agron. J. 79:779-786.

Johnson, N. C., Graham, J. H., and Smith, F. A. 1997. Functioning of mycorrhizal associations along the mutualism-parasitism continuum. New Phytol. 135:575-585.

Kaiser, D. E., Lamb, J. A., Bloom, P. R., and Hernandez, J. A. 2014. Comparison of field management strategies for preventing iron deficiency chlorosis in soybean. Agron. J. 106:1963-1974.

Khalil, S., Loynachan, T. E., and Tabatabai, M. A. 1994. Mycorrhizal dependency and nutrient-uptake by improved and unimproved corn and soybean cultivars. Agron. J. 86:949-958.

Koske, R. E., and Tessier, B. 1983. A convenient, permanent slide mounting medium. Mycol. Soc. Am. Newsl. 34:59.

Latef, A. A. H. A., Hashem, A., Rasool, S., Abd Allah, E. F., Alqarawi, A. A., Egamberdieva, D., Jan, S., Anjum, N. A., and Ahmad, P. 2016. Arbuscular mycorrhizal symbiosis and abiotic stress in plants: A review. J. Plant Biol. 59:407-426

Liesch, A. M., Diaz, D. A. R., Mengel, D. B., and Roozeboom, K. L. 2012. Interpreting relationships between soil variables and soybean iron deficiency using factor analysis. Soil Sci. Soc. Am. J. 76:1311-1318.

Miller, D. R., Chen, S. Y., Porter, P. M., Johnson, G. A., Wyse, D. L., Stetina, S. R., Klossner, L. D., and Nelson, G. A. 2006. Rotation crop evaluation for management of the soybean cyst nematode in Minnesota. Agron. J. 98:569-578.
Monson, M., and Schmitt, D. P. 2004. Economics. Pages 41-53 in: Biology and management of the soybean cyst nematode. D. P. Schmitt, J. A. Wrather, and R. D. Riggs, eds. Schmitt \& Associates of Marceline, Marceline, MO, U.S.A.

Morris, D. R., Loeppert, R. H., and Moore, T. J. 1990. Indigenous soil factors influencing iron chlorosis of soybean in calcareous soils. Soil Sci. Soc. Am. J. 54:1329-1336.

Naeve, S. L. 2006. Iron deficiency chlorosis in soybean: Soybean seeding rate and companion crop effects. Agron. J. 98:1575-1581.

Naher, U. A., Othman, R., and Panhwar, Q. A. 2013. Beneficial effects of mycorrhizal association for crop production in the tropics-A review. Int. J. Agric. Biol. 15:1021-1028.

Nogueira, M. A., and Cardoso, E. J. B. N. 2002. Interações microbianas na disponibilidade e absorção de manganês por soja [Microbial interactions on manganese availability and uptake by soybean]. Pesqui. Agropecu. Bras. 37: 1605-1612.

Pawlowski, M. L., and Hartman, G. L. 2020. Impact of arbuscular mycorrhizal species on Heterodera glycine. Plant Dis. 104:2406-2410.

Pedersen, P., Tylka, G. L., Mallarino, A., MacGuidwin, A. E., Koval, N. C., and Grau, C. R. 2010. Correlation between soil pH, Heterodera glycines population densities, and soybean yield. Crop Sci. 50:1458-1464.

Peters, J. B., Speth, P. E., Kelling, K. A., and Borges, R. 2005. Effect of soil pH on soybean. University of Wisconsin Soil Science Extension. https:// extension.soils.wisc.edu/wcmc/effect-of-soil-ph-on-soybean-yield/

Pinochet, J., Calvet, C., Camprubi, A., and Fernandez, C. 1996. Interactions between migratory endoparasitic nematodes and arbuscular mycorrhizal fungi in perennial crops: A review. Plant Soil 185:183-190.

Porcel, R., and Ruiz-Lozano, J. M. 2004. Arbuscular mycorrhizal influence on leaf water potential, solute accumulation, and oxidative stress in soybean plants subjected to drought stress. J. Exp. Bot. 55:1743-1750.

Ravelombola, W. S., Qin, J., Shi, A., Nice, L., Bao, Y., Lorenz, A., Orf, J. H., Young, N. D., and Chen, S. Y. 2019. Genome-wide association study and genomic selection for soybean chlorophyll content associated with soybean cyst nematode tolerance. BMC Genomics 20:904.

Rodríguez-Echeverría, S., de la Peña, E., Moens, M., Freitas, H., and van der Putten, W. H. 2009. Can root-feeders alter the composition of AMF communities? Experimental evidence from the dune grass Ammophila arenaria. Basic Appl. Ecol. 10:131-140.

Sankaranarayanan, C., Rajeswari, S., and Sundarababu, R. 2001. Influence of moisture and $\mathrm{pH}$ on the efficiency of VA-mycorrhiza, Glomus mosseae (Nicol \& Gerd.) Gerd. \& Trappe against Meloidogyne incognita (Kofoid and White) Chitw. on blackgram (Vigna mungo L.) Hepper. J. Biol. Control 15: 69-72.

Schreiner, R. P., and Pinkerton, J. N. 2008. Ring nematodes (Mesocriconema xenoplax) alter root colonization and function of arbuscular mycorrhizal fungi in grape roots in a low P soil. Soil Biol. Biochem. 40:1870-1877.

Schulte, E. E., Walsh, L. M., Kelling, K. A., Bundy, L. G., Bland, W. L., Wolkowski, R. P., Peters, J. B., and Sturgul, S. J. 2005. Management of Wisconsin Soils, 5th ed. Coop. Ext. Publ. A3588. University of WisconsinExtension, Madison, WI, U.S.A.

Smith, F. A., and Smith, S. E. 1997. Structural diversity in (vesicular)arbuscular mycorrhizal symbioses. New Phytol. 137:373-388.

Sommerville, R. I., and Davey, K. G. 2002. Diapause in parasitic nematodes: A review. Can. J. Zool. 80:1817-1840.

Suresh, C. K., Bagyaraj, D. J., and Reddy, D. D. R. 1985. Effect of vesiculararbuscular mycorrhizae on survival, penetration and development of rootknot nematode in tomato. Plant Soil 87:305-308.

Todd, T. C., Winkler, H. E., and Wilson, G. W. T. 2001. Interaction of Heterodera glycines and Glomus mosseae on soybean. J. Nematol. 33:306-310.

Tylka, G. L., Hussey, R. S., and Roncadori, R. W. 1991. Interactions of vesicular-arbuscular mycorrhizal fungi, phosphorus, and Heterodera glycines on soybean. J. Nematol. 23:122-133.

Valetti, L., Iriarte, L., and Fabra, A. 2016. Effect of previous cropping of rapeseed (Brassica napus L.) on soybean (Glycine max) root mycorrhization, nodulation, and plant growth. Eur. J. Soil Biol. 76:103-106.

Wallace, A. 1988. Iron chlorosis induced by detopping soybeans. J. Plant Nutr. 11:793-796.

Winkler, H. E., Hetrick, B. A. D., and Todd, T. C. 1994. Interactions of Heterodera glycines, Macrophomina phaseolina, and mycorrhizal fungi on soybean in Kansas. J. Nematol. 26:675-682.

Zheng, L., and Ferris, H. 1991. Four types of dormancy exhibited by eggs of Heterodera schachtii. Rev. Nematol. 14:419-426.

Zhou, J. 2009. Interactive effects of soybean cyst nematode, mycorrhizal fungi, and iron-deficiency on soybean nutrients and growth. University of Minnesota, St. Paul, MN, U.S.A. 